\title{
Vom Land und von anderen Leuten
}

Erhard Taverna

Wie es um die schweizerische Befindlichkeit steht, lässt sich in Solothurn jeden Januar an der Filmleinwand ablesen. Die Dimensionen passen zum Land: kurze Fusswege vor malerischer $\mathrm{Ku}-$ lisse, eine ruhige Aare mit Nebel, Vollmond und Sonnenschein, abends gähnende Leere. Die Auswahl ist mit 248 Titeln und 161 Stunden Spieldauer beachtlich, sie umfasst Musikclips, Animations-, Experimental-, Dokumentar- und Spielfilme, eine Retrospektive, ein Rahmenprogramm und, heuer zum letzten Mal, die Preisverleihung am Mittwoch. Wie immer verbreitet der Bundesrat Optimismus, wie immer wird über die Filmförderung gestritten, und wie immer wird bei jeder Vorstellung eine Zweisprachigkeit demonstriert, die sich in zwei bis drei Sätzen erschöpft und das zum Inhalt hat, was schon jeder weiss. Wie meistens sind die Spielfilme solide gedreht und nett erzählt, etwas bieder und leicht depressiv. Kassenfüllender Klamauk ist nicht jedes Jahr zu haben, was dann den Marktanteil des Schweizer Films auf fünf Prozent absacken lässt. Doch eine zuverlässige Fundgrube sind die Dokus - wer sich auf sie einlässt, begegnet überraschenden Einsichten, lernt interessante Regisseure und Regisseurinnen kennen, betritt verborgene Zonen im In- und Ausland und erweitert seinen Horizont. Medizinische Themen gehören zum festen Repertoire, ein Chirurgenteam im Universitätsspital: «Le théâtre des opérations»; ein unbekannter schwarzer Gärtner, der Barnard bei seiner ersten Herztransplantation unterstützte: «Hidden heart»; Filme über den Umgang mit Alter: «Les fleurs vues de dessus» und Demenz: «Heute ist nicht Morgen». Drei inhaltlich verschiedene Filme zeigen starke Frauen und die Folgen fehlender Sexualaufklärung und Familienplanung.

\section{«Egoïste - Lotti Latrous» \\ von Stephan Anspichler, 92 Minuten}

Die 1953 in Dielsdorf geborene Lotti Latrous betreibt seit zehn Jahren ein Hospiz für aidskranke Menschen in Abidjan, der grössten Stadt der Elfenbeinküste. Im vom Bürgerkrieg und Armut geschwächten 16-Millionen-Land in Westafrika sind Sexualaufklärung und Familienplanung ein frustrierendes Unternehmen. Die «Schweizerin des Jahres 2004» bietet Sterbenden eine Zuflucht im «Centre l'Espoir» und HIV-infizierten Kindern eine Bleibe im Waisenhaus. Zum Betrieb gehören eine Tagesklinik mit Labor und Apotheke, wobei die Hilfe auch Lebensmittel, Kleider, Kleinkredite, Operationskosten und Beiträge an die Schulbildung umfasst. Der Film zeigt die täglichen Fahrten in die Slums, die Krankentransporte, Gespräche mit Angehörigen, Sprechstunden und Sterbebegleitungen. Entstanden ist das Porträt einer mutigen Frau, die sich als süchtig

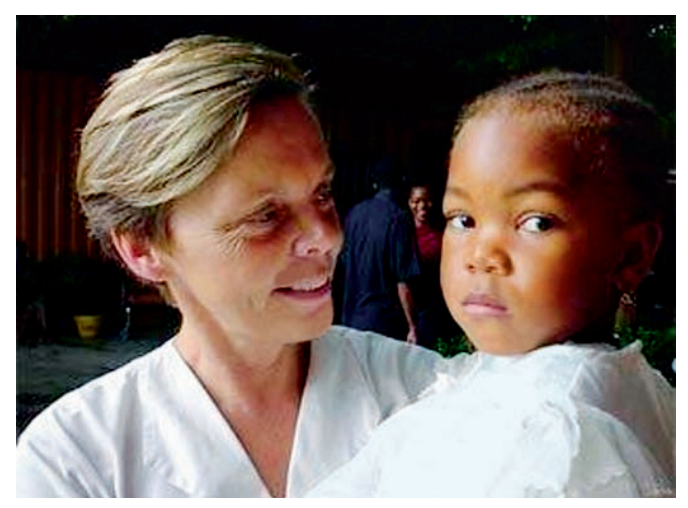

und egoistisch bezeichnet, weil sie ohne diese Arbeit nicht mehr leben könne. Selbstverwirklichung auf Kosten der Familie? Der Ehemann, der für Nestlé in Kairo arbeitet, und die drei Kinder, zwei davon in der Westschweiz, kommen ausführlich zu Wort. Frau Latrous kämpft an zwei Fronten, gegen das Elend der Kranken und mit dem eigenen Gewissen. Eine Frau verlässt den Ehemann und eine minderjährige Tochter für eine grössere Aufgabe - wäre sie ein Mann, wäre das kein Problem. Sie ist zum Star geworden, der in Europa erfolgreich Spendengelder eintreibt. Eine doppelt zwiespältige Rolle, denn einerseits verachtet sie die wohlhabende Gesellschaftsschicht, aus der sie selber stammt, und andererseits ist sie immer der betriebsame Mittelpunkt ihrer Patientenwelt. Eine weisse Solistin in einem schwarzen Land, dessen öffentliche Spitäler keine Aidskranken aufnehmen. Familiendrama oder Heldenepos? Die ausgiebige Selbstinszenierung weckt auch kritische Gedanken. Doch wer wollte mit ihr tauschen?

\section{«Memory Books» von Christa Graf, 90 Minuten}

In Uganda ist die Lage nicht weniger schlimm. Über zwei Millionen Waisen leben auf der Strasse oder in Heimen. Dabei hat die Regierung ein vorbildliches Aufklärungsprogramm umgesetzt, das 


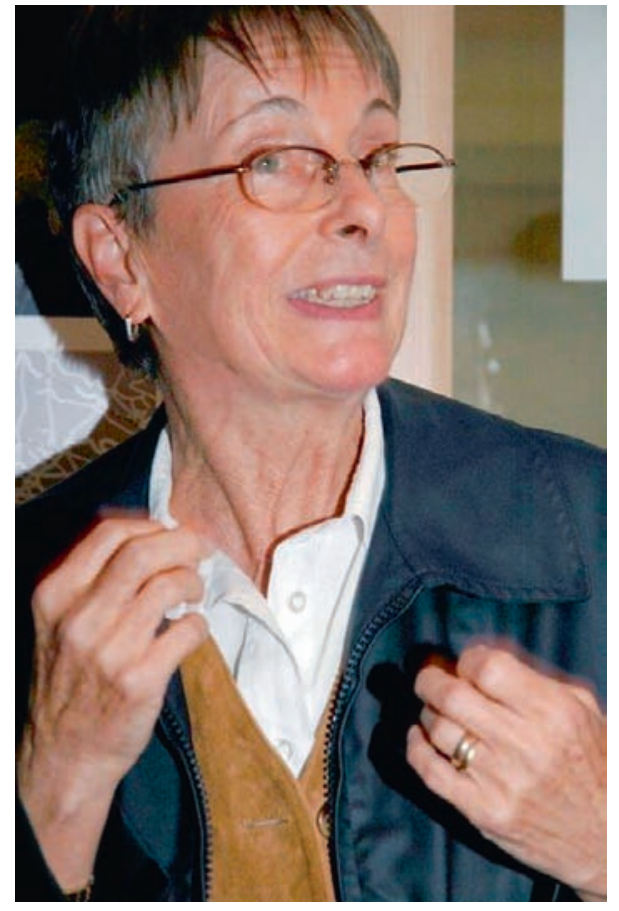

auch nachweisbare Erfolge zeigt, wobei heute evangelikale Gruppen aus den USA mit Kondomverboten und realitätsfremden Moralforderungen die bisherigen Anstrengungen zunehmend torpedieren. In diesem Film kommen die Kranken selbst zu Wort. Die unscheinbare Heldin ist die Krankenschwester Christine, eine HIV-infizierte mütterliche Frau, die im Spital den wartenden Frauen einfühlsam das Testresultat mitteilt, Kranke liebevoll betreut, zuhause Waisen aufnimmt und in einem Selbsthilfeprojekt die infizierten Frauen im Schreiben eines «Memory Book» unterrichtet. Dieses Erinnerungsbuch, an dem eine Frau kommentierend schreibt, ist ihre Vorbereitung auf den eigenen Tod, ein Buch, das den Nachkommen erklärt, woher sie stammen, wer ihre Eltern waren, wie sie selber auf die Welt kamen und ihre Jahre lebten, als es noch ein $\mathrm{Zu}$ hause gab. Kinderzeichnungen und Fotos ergänzen die Familiengeschichte, die Ermahnungen für die Zukunft, die Anekdoten und Erzählungen; ein Abschieds- und Totenbuch, Dokument einer Tragödie. Für verwöhnte Schweizer ist die Würde dieser Frauen und Kinder fast unfassbar. Trauer, aber auch Tanz und Gesänge wechseln wie der Sonnenschein und der Regen über dem grünen, hügeligen Land. Ein Arzt, der auch als Medizinmann im traditionellen Gewand die Patienten berät, weiss um die Wurzeln der afrika- nischen Identität. Es brauche beides, die westliche Medizin und den Ahnenkult, das moderne Spital und die Riten der Vergangenheit. Ein sehr berührendes und eindrucksvolles Zeugnis einer unfassbaren, zu Tränen rührenden Katastrophe.

\section{«La Reina del Condón» von Silvana Ceschi und Reto Stamm, 75 Minuten}

Die Ostsee 1961, ein Schiff läuft vom Stapel im Auftrag des neuen kubanischen Regimes. Die junge Studentin Monika Krause verliebt sich in den Kapitän und verlässt nach einer Blitzehe die DDR. Zwischen Havanna und Rostock entsteht aus Rückblenden, Monologen und Kommentaren beider Söhne die phantastische Geschichte der «Königin des Kondoms». Über Beziehungen zur Nomenklatura wurde die junge Deutsche beauftragt, ein Aufklärungsbuch zu schaffen, das unter anderem den vielen Teenagerschwangerschaften ein Ende setzen sollte. Da es an Vorbildern fehlt, schuf sie ein bebildertes Lehrbuch, das hierzulande in dieser Zeit nicht möglich gewesen wäre. Monika Krause wurde zur Aufklärungsministerin, mutig, kreativ und engagiert, stets im Kampf gegen Machismo und Zensur, Traditionen und Vorurteile. Sie war Oswalt Kolle und Tante Martha in Personalunion, aber auch populäre Fernsehsprecherin und unermüdliche Wanderpredigerin von einer Schule zur anderen. Sie machte das Kondom noch vor Aids öffentlich und löste eine Debatte über die Diskriminierung der Schwulen aus. Auch sie bezahlte ihren Einsatz mit zunehmender Entfremdung und Unverständnis, was zur Scheidung führte. 1989 verliess sie die Insel mit beiden Söhnen und kehrte in eine Heimat zurück, die es bereits nicht mehr gab. Der Film ist auch humorvoll, vor allem wenn der eine Sohn mit dem antiquarischen Buch in den Strassen Havannas herumläuft, um Zeitzeugen auszufragen, oder davon berichtet, wie er von den Mitschülern wegen seiner Mutter gehänselt wurde. Der revolutionäre Schwung ist längst Geschichte, doch ihre Arbeit war nicht umsonst. Die HIV-/Aids-Rate ist in Kuba vergleichsweise niedrig, die Prävention fortgeschrittener als sonst in der Karibik oder in Lateinamerika. Während heute ihr Ex in der Sonne eine Zigarre raucht, füttert sie am Winterstrand die Enten. Mit diesem Beitrag wird eine längst fällige Ehrenschuld abgetragen und zudem, gut schweizerisch, ein Stück Versöhnung in die Wege geleitet. 